\title{
Stress Analysis of Multi-Layered Hybrid Composite Pipes Subjected to Internal Pressure
}

\author{
İsmail Yasin Sülü \\ İn̈nü University, Department of Mechanical Engineering, Malatya, Turkey \\ E-mail address: ismail.sulu@inonu.edu.tr \\ Received date: December 2016 \\ Accepted date: December 2016
}

\begin{abstract}
The stress analysis of multi-layered hybrid composite pipes with symmetrical orientation angles, under internal pressure, was investigated. The codes of numerical models were created in ANSYS software for numerical analyses. Two inner surfaces of first model are E-glass fibre/epoxy and its two outer surfaces are carbon/epoxy (AS4/3501-6). Inner surfaces of second model are carbon/epoxy (AS4/3501-6) and its outer surfaces are E-glass fibre/epoxy. The problem was studied using a computational tool based on the Finite Element Method (FEM). Each layer of the composite pipes was examined with different orientation angles. The hoop and shear stresses were obtained numerically for each layer. Also, radial, tangential, axial and shear stresses were determined in the thickness direction of the composite pipes. The shear extension coupling was considered because the lay-up angles with $[+\theta,-\theta]_{s}$ layers were in the different radii.
\end{abstract}

Keywords: Hybrid structures, mechanical behavior, composite pipes, finite element analysis (FEA)

\section{Introduction}

Hybrid composite pipes are used extensively in industry. Composite structures have several advantages, including high stiffness and strength, corrosion resistance, and thermal resistance [1]. Therefore, as manufacturing technology has developed, there has been growing interest in the application of hybrid composite pipes.

Research is being conducted to determine the behaviors of various composite pipes under different loadings. One of the important mechanical properties of a composite pipe is its service life. This makes it imperative to determine a piping system's leakage integrity and reliability. This depends on the strong lay-up in the principal pipe directions, which is determined with monotonic biaxial testing of filament-wound pipe [2] and testing other parameters during manufacturing. Therefore, failure analyses are conducted to determine the service life of the composite pipes. A few failure investigations have been reported in the literature, and they reported optimum failure loads, stresses, pipe radius, layer thickness, and winding angles [3-8]. Furthermore, a general stress analysis for thick or thin multi-layered composite cylinders under hydrothermal loadings was developed by Sayman [9]. Zhao et al. [10] considered the stress analysis of a multi-layered composite cylinder with local delamination. In their work, they proposed a realistic analytical model and developed a system of differential difference equations with constant coefficients by introducing a transformation of super-subscripts. Also, they indicated that all stresses in the composite layers were lower than the stresses in the internal metal cylinder. In addition, there are several studies related to pipes in the literature. Arjomandi and Taheri [11] determined that the behaviors of sandwich pipes are subject to pure bending, which is one of the governing loading conditions for offshore pipelines. Tran et al. [12] designed hybrid elastomeric composite panels. A finite element model was developed to 
understand the deformation and failure mechanisms of a multilayered elastomer/fiber-reinforced polymer (FRP) composite panel under blast. Ridzuan et al. [13] were investigated the thermal behavior and dynamic mechanical analysis of Pennisetumpurpureum/glass-reinforced hybrid composites. Pennisetumpurpureum fibers were respectively determined at $64,64,67$, and $63{ }^{\circ} \mathrm{C}$, by dynamic mechanical analysis (DMA). Essabir et al. [14] modified oil palm fibers and clay particles and then incorporated to reinforce high density polyethylene. The hybrid composites were prepared and compounded with a com- patibilizer by twin-screw extrusion followed by injection molding. The evolution of thermal, mechanical, and dynamic mechanical performances of the hybrid composites as a function of filler content was investigated.

In this study, we used hybrid composite pipes, which made of E-glass fiber/ epoxy and carbon/epoxy (AS4/3501-6), with different orientation angles. The code for a numerical model was created in ANSYS software for numerical analysis. The hoop, axial and shear stresses also were determined for different orientation angles. In addition, tangential, radial, axial and shear stresses were obtained numerically for hybrid composite pipes. We also investigated the mechanical properties of hybrid composite pipes with four layers. Also, hybrid composite pipes were compared and showed be used under high internal pressure and they are important for pipes systems in industry were presented.

\section{Non-Linear Finite Element Modeling}

he multi-layered, filament-wound composite pipes shown in Fig. 1 have four plies [1]. Table 1 and Table 2 show material constants from the literature [15-18]. The composite pipes were manufactured using E-glass fibers/epoxy and carbon/epoxy (AS4/3501-6).

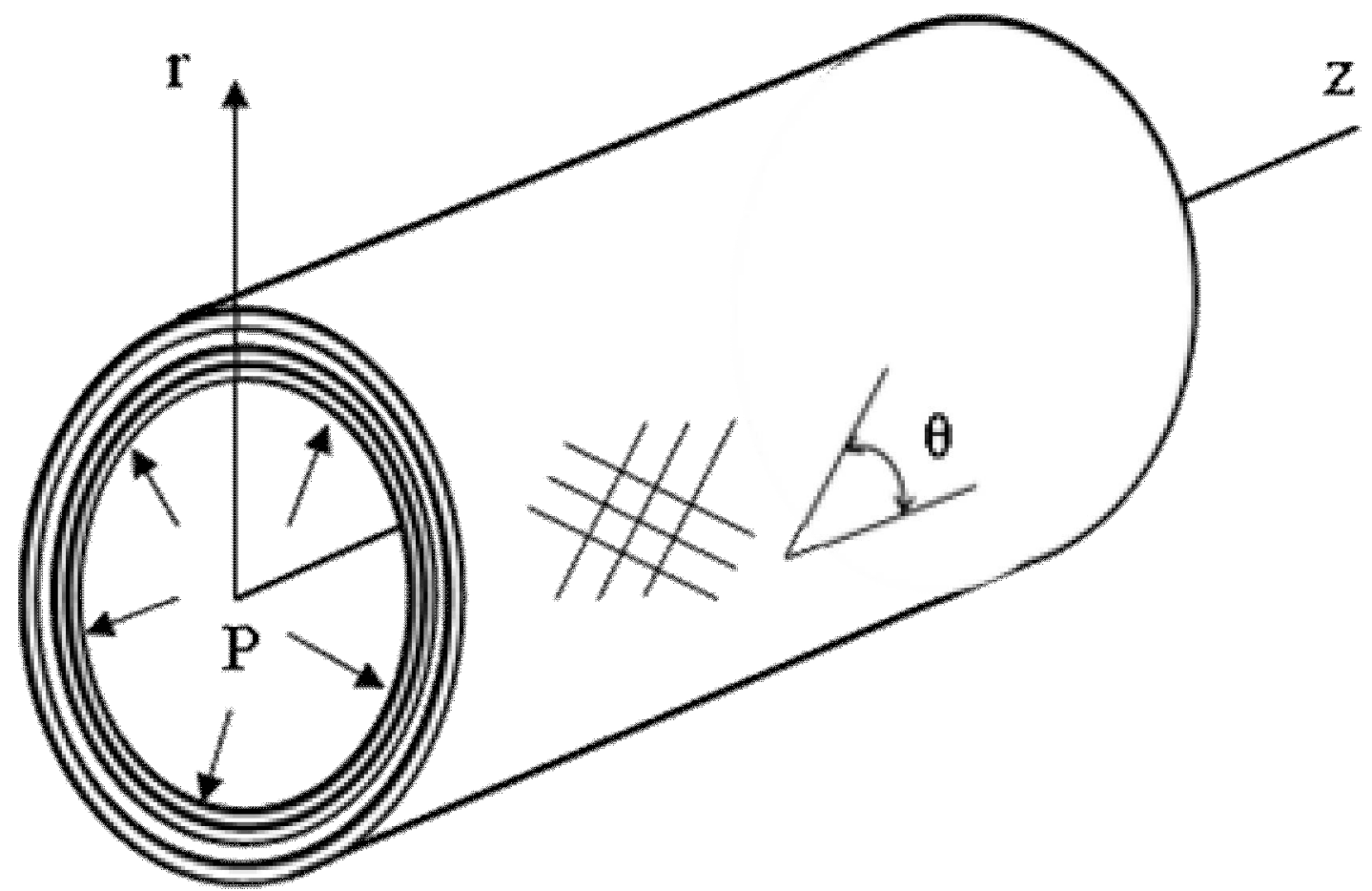

Fig. 1. Multi-layered composite pipe

Structural analyses were conducted in order to investigate the mechanical behavior of the layered hybrid composite pipes under internal pressure loading. The orientation angles and layer sequence were important for the analyses. Therefore, they were used in Table 3 in which the orientation angles are shown. In the study, we used the finite element method (FEM), and the numerical model was 
prepared in ANSYS 14.5 software based on FEM. The model code was created with the SOLID186 element in ANSYS software.

Table 1. Material constants for AS4/3501-6 carbon/epoxy [15, 17]

\begin{tabular}{ll}
\hline Properties & E-Glass \\
\hline $\mathrm{E}_{\mathrm{x}}(\mathrm{MPa})$ & 113600 \\
$\mathrm{E}_{\mathrm{y}}(\mathrm{MPa})$ & 9650 \\
$\mathrm{E}_{\mathrm{z}}(\mathrm{MPa})$ & 9650 \\
$\mathrm{G}_{\mathrm{xy}}(\mathrm{MPa})$ & 6000 \\
$\mathrm{G}_{\mathrm{yz}}(\mathrm{MPa})$ & 3800 \\
$\mathrm{G}_{\mathrm{xz}}(\mathrm{MPa})$ & 6000 \\
$v_{\mathrm{xy}}$ & 0.334 \\
$v_{\mathrm{yz}}$ & 0.54 \\
$v_{\mathrm{xz}}$ & 0.328 \\
$\mathrm{X}_{\mathrm{T}}(\mathrm{MPa})$ & 1720 \\
$\mathrm{Y}_{\mathrm{T}}(\mathrm{MPa})$ & 55.2 \\
$\mathrm{Z}_{\mathrm{T}}(\mathrm{MPa})$ & 55.2 \\
$\mathrm{X}_{\mathrm{C}}(\mathrm{MPa})$ & 1170 \\
$\mathrm{Y}_{\mathrm{C}}(\mathrm{MPa})$ & 207 \\
$\mathrm{Z}_{\mathrm{C}}(\mathrm{MPa})$ & 207 \\
$\mathrm{~S}_{\mathrm{xy}}(\mathrm{MPa})$ & 103 \\
$\mathrm{~S}_{\mathrm{yz}}(\mathrm{MPa})$ & 82.7 \\
$\mathrm{~S}_{\mathrm{xz}}(\mathrm{MPa})$ & 82.7 \\
\hline
\end{tabular}

Table 2. Material constants for E-Glass [18]

\begin{tabular}{ll}
\hline Properties & E-Glass \\
\hline $\mathrm{E}_{\mathrm{x}}(\mathrm{MPa})$ & 25760 \\
$\mathrm{E}_{\mathrm{y}}(\mathrm{MPa})$ & 8824 \\
$\mathrm{G}_{\mathrm{xy}}(\mathrm{MPa})$ & 4965 \\
$\mathrm{G}_{\mathrm{yz}}(\mathrm{MPa})$ & 3472 \\
$\mathrm{G}_{\mathrm{xz}}(\mathrm{MPa})$ & 4965 \\
$v_{\mathrm{xy}}$ & 0.14 \\
$v_{\mathrm{yz}}$ & 0.22 \\
$v_{\mathrm{xz}}$ & 0.14 \\
$\mathrm{X}_{\mathrm{T}}(\mathrm{MPa})$ & 699.98 \\
$\mathrm{Y}_{\mathrm{T}}(\mathrm{MPa})$ & 78.29 \\
$\mathrm{Z}_{\mathrm{T}}(\mathrm{MPa})$ & 78.29 \\
$\mathrm{X}_{\mathrm{C}}(\mathrm{MPa})$ & 382.63 \\
$\mathrm{Y}_{\mathrm{C}}(\mathrm{MPa})$ & 119.91 \\
$\mathrm{Z}_{\mathrm{C}}(\mathrm{MPa})$ & 119.91 \\
$\mathrm{~S}(\mathrm{MPa})$ & 85.92 \\
\hline
\end{tabular}


Table 3. Orientation angles used in studies

Orientation angles

$45 /-45 /-45 / 45$

$55 /-55 /-55 / 55$

$60 /-60 /-60 / 60$

$75 /-75 /-75 / 75$

As shown in Fig. 2, $r_{j}$ is layer radius $(\mathrm{j}=1,2,3,4), r_{i n}$ is inner radius and $r_{\text {out }}$ is the outer radius of the composite pipe, and $R$ is radius ratio in the radial direction. It was assumed that, for hybrid composite pipes, internal pressure $(P)$ is $10 \mathrm{MPa}$, the inner radius is $50 \mathrm{~mm}$, and the thickness of each layer is $0.5 \mathrm{~mm}[1]$.

$$
R=\frac{r_{j}-r_{\text {in }}}{r_{\text {out }}-r_{i n}}
$$

In the FEM studies, multi-layered hybrid composite pipes subject to internal pressure by using different orientation angles were simulated, as shown in Fig. 3. In the analysis, we considered the elastic solution based on the uniaxial stress behaviors of using material constants of carbon fiber and E-glass fiber from the literature. The material properties used in the FE analysis are given in Table 1 and Table 2, respectively.

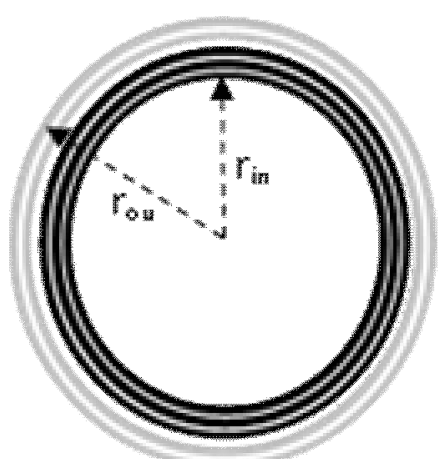

Fig. 2. Layered composite pipe in 2-D

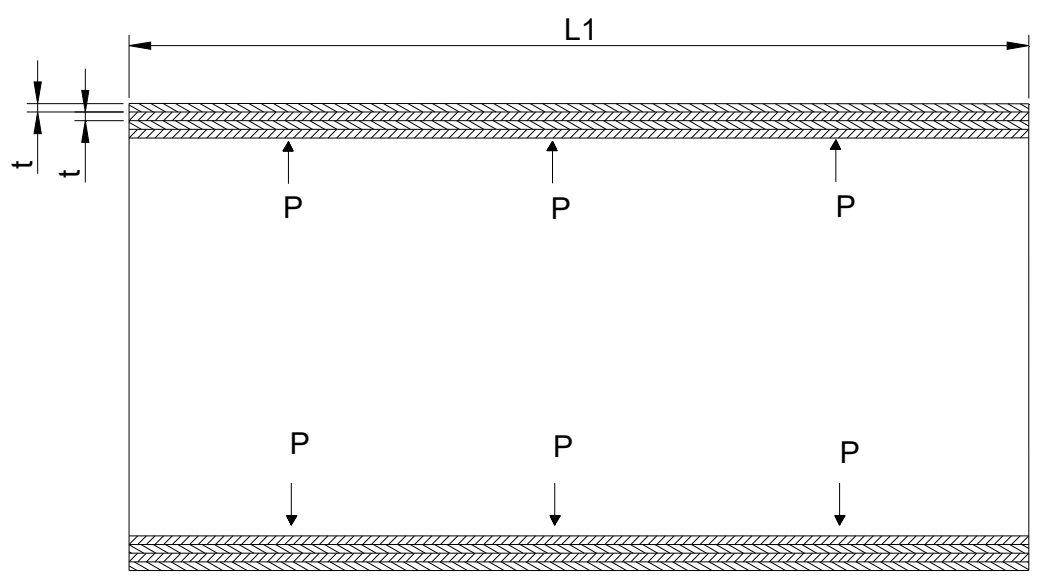

Fig. 3. Finite element model 
The stress analysis of hybrid composite pipes under internal pressure was conducted. In the analysis of hybrid composite pipes, 3D non-linear FEM was conducted. The ANSYS code version 14.5 and the 20-node iso-parametric quadrilateral solid element, SOLID186, were used for the composite pipes. The 20-node element was defined with twenty nodes with three degrees of freedom at each node, i.e., translation in the nodal $\mathrm{x}, \mathrm{y}$ and $\mathrm{z}$ directions (in Fig.4).

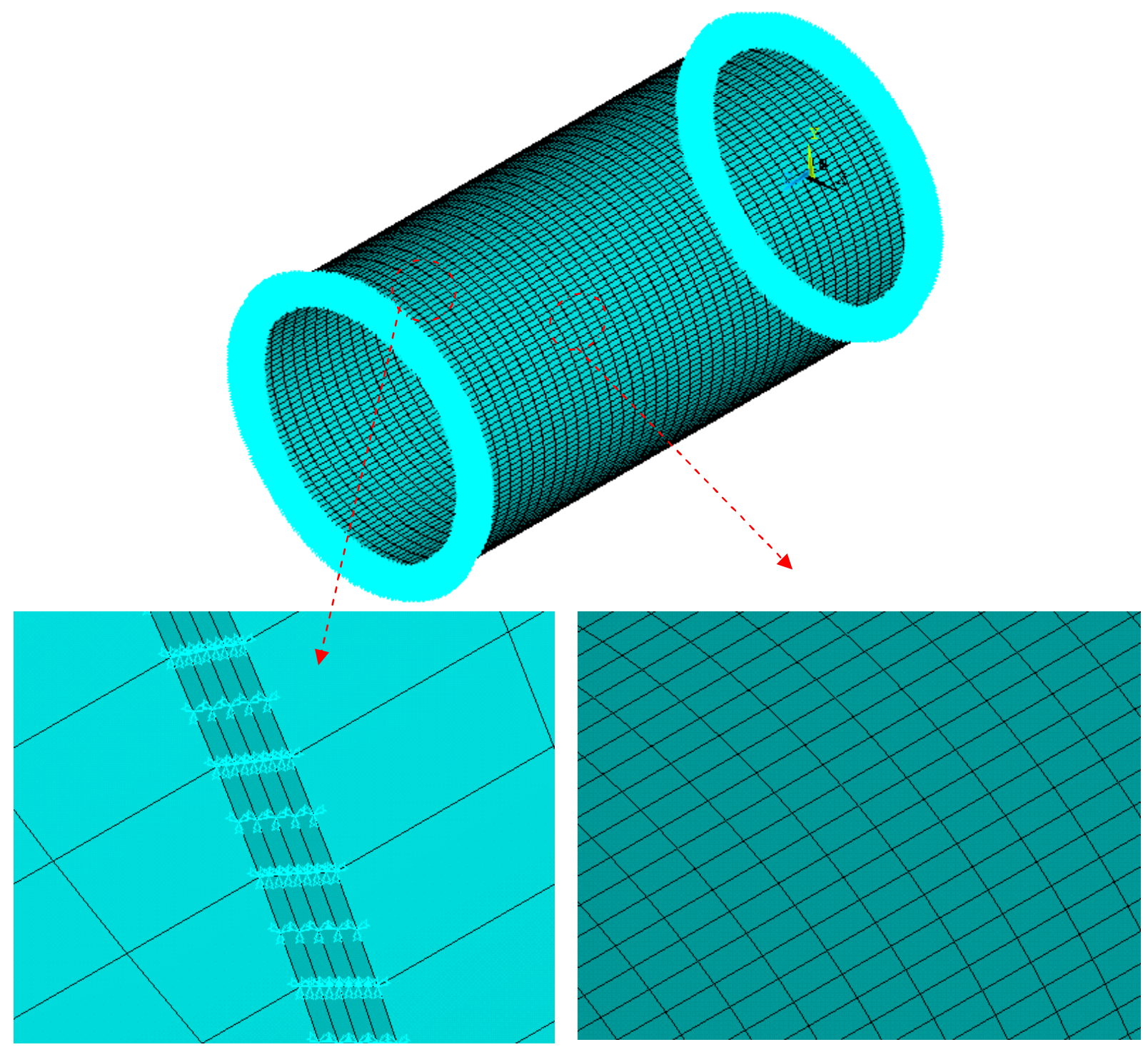

Fig. 4. Mesh details and boundary condition

In the multi-layered composite pipes, the thicknesses of each layer were considered to be $0.5 \mathrm{~mm}(\mathrm{t})$ and the length of the composite pipes was $200 \mathrm{~mm}$ (L1). 


\section{Results and Discussion}

\subsection{The stresses on layers}

In the numerical analyses, models are created from the code generated in ANSYS software. They were solved for the orientation angles shown in Table 3. Hoop, axial and shear stresses were numerically calculated in each layer. Fig. 5 and Fig. 6 show the influence of orientation angles in each layer. The stresses of $\left[45^{0} /-45^{0}\right]_{\mathrm{s}}$ and $\left[55^{0} /-55^{0}\right]_{\mathrm{s}}$ lay-up was greater than the others. In other words, if the value of the angle decreases, shear stresses also decrease.

Fig. 5a and Fig. 6a shows the behavior of shear stress for various orientation angles. Fig. 5a and Fig. 6a shows that, the shear stresses for all orientation angles are almost the same from the inner surface to the outer surface of the pipes. As shown in Fig. 5a and Fig. 6a, the all orientation angles showed similar behavior from the inside to the outside of the pipe. Moreover, the effects of the orientation angles can be seen for the hoop stresses in Fig. 5b and Fig. 6b. Also, the orientation angles affect strength of composite pipes, and they are important for orientation angles and the order of the layers. Fig. $5 \mathrm{~b}$ and Fig. $6 \mathrm{~b}$ shows that the layer angles effectively affect hoop stresses. The stresses of $\left[45^{\circ} /-\right.$ $\left.45^{0}\right]_{\mathrm{s}}$ and $\left[55^{\circ} /-55^{0}\right]_{\mathrm{s}}$ lay-up was greater than the others. As seen Fig. 5c and Fig. 6c, the axial stresses of $\left[45^{\circ} /-45^{0}\right]_{\mathrm{s}}$ are the greatest from the inner surface to the outer surface of the pipes than other.

In summary, it can be said that mechanical behavior of hybrid composite pipes with $\left[45^{0} /-45^{0}\right]_{\mathrm{s}}$ orientation angles is different from the behavior at other angles. Also, the stresses of hybrid composite pipes, inner surfaces of model are carbon/epoxy (AS4/3501-6) and its outer surfaces are E-glass fibre/epoxy, are the greater than other.

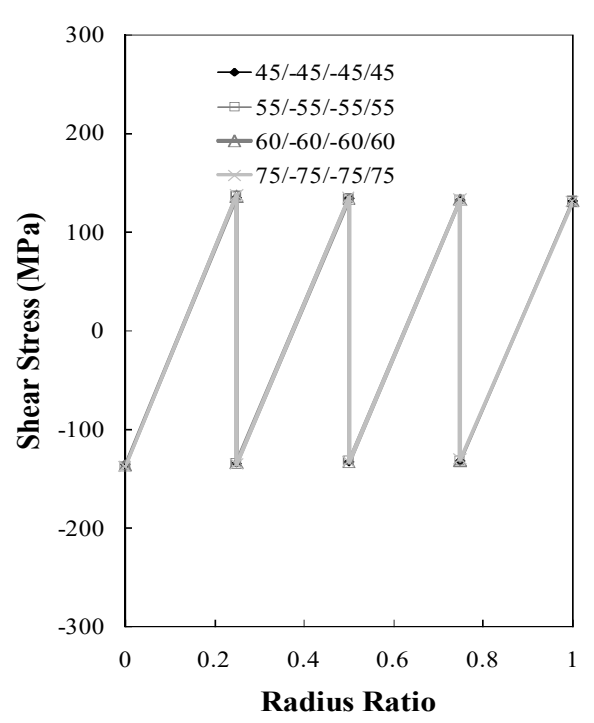

(a)

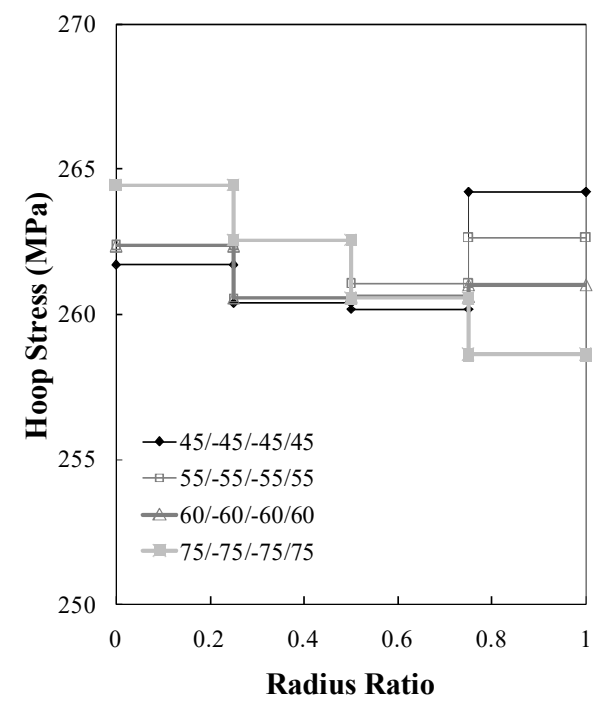

(b) 


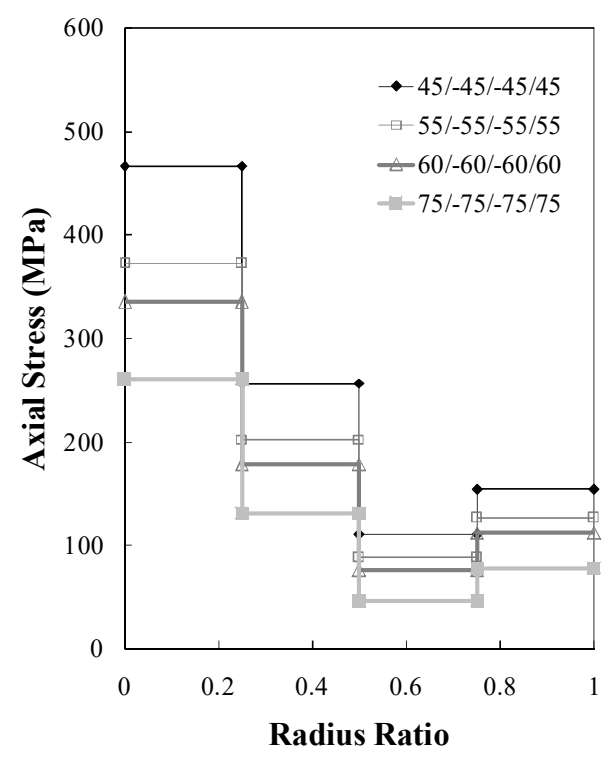

(c)

Fig. 5. The distribution compared of (a) shear stress, (b) hoop stress, (c) axial stress in layers through thickness direction for inner surfaces E-glass fibre/epoxy and outer surfaces carbon/epoxy (AS4/35016)

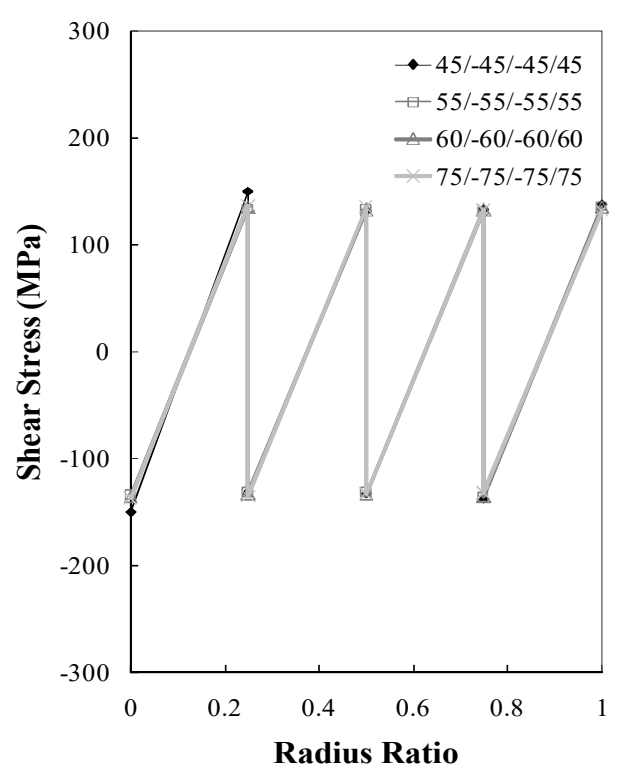

(a)

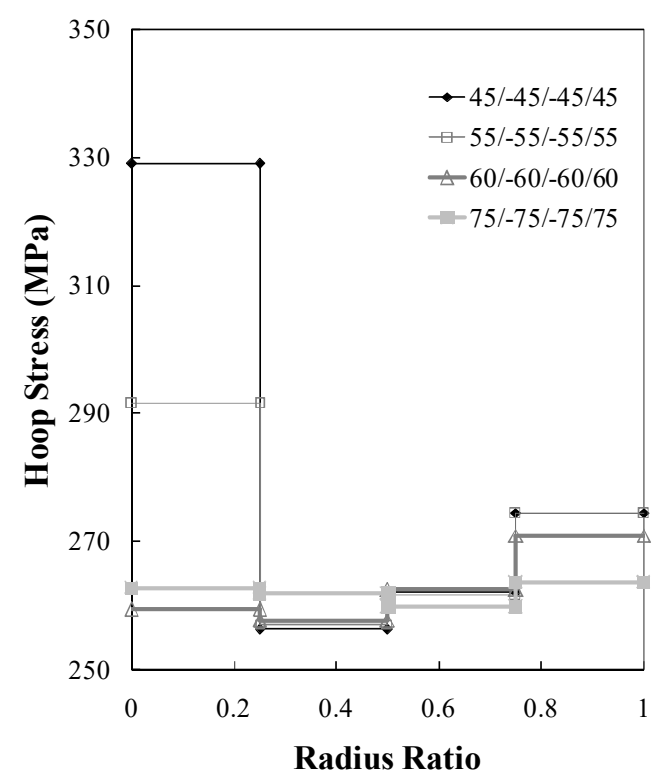

(b) 


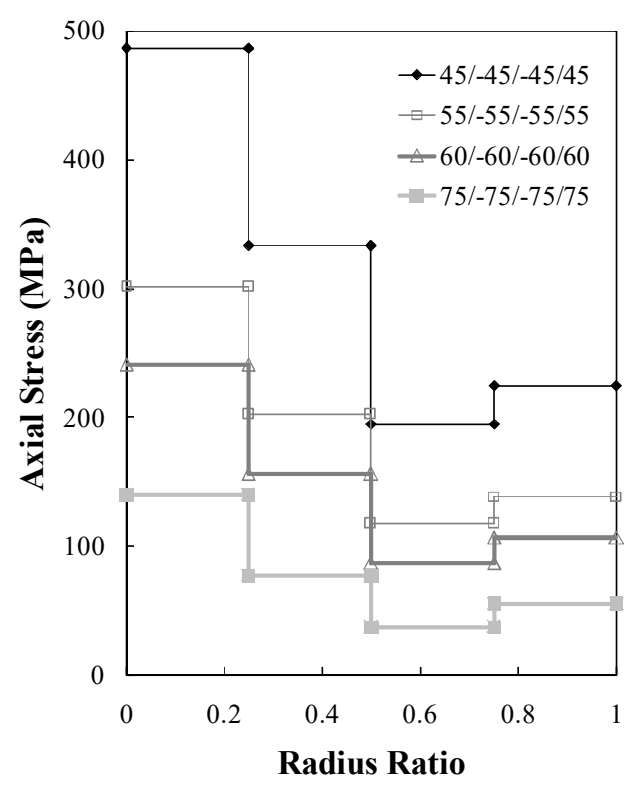

(c)

Fig. 6. The distribution compared of (a) shear stress, (b) hoop stress, (c) axial stress in layers through thickness direction for inner surfaces carbon/epoxy (AS4/3501-6) and outer surfaces Eglass fibre/epoxy

\subsection{Effect of orientation angles and the order of layers on stress distribution}

The models were generated using codes in the ANSYS package software for numerical analyses. Analyses were carried out for the orientation angles shown in Table 3. Internal pressures were determined as $\mathrm{P}=10 \mathrm{MPa}$ during the analyses.

Radial, tangential, axial and shear stresses were calculated using numerically obtained internal pressure values. When Fig. 7 and Fig. 8 are examined, the effects of orientation angles on every layer of the composite pipe. It can be seen in Fig. 7 and Fig. 8 that the highest stresses on the pipe surface subject to internal pressure are those that occur in the radial direction. Whereas other stresses put forth different behaviors according to the effect of the orientation angles and in order of E-glass fibre/epoxy and carbon fiber/epoxy. 


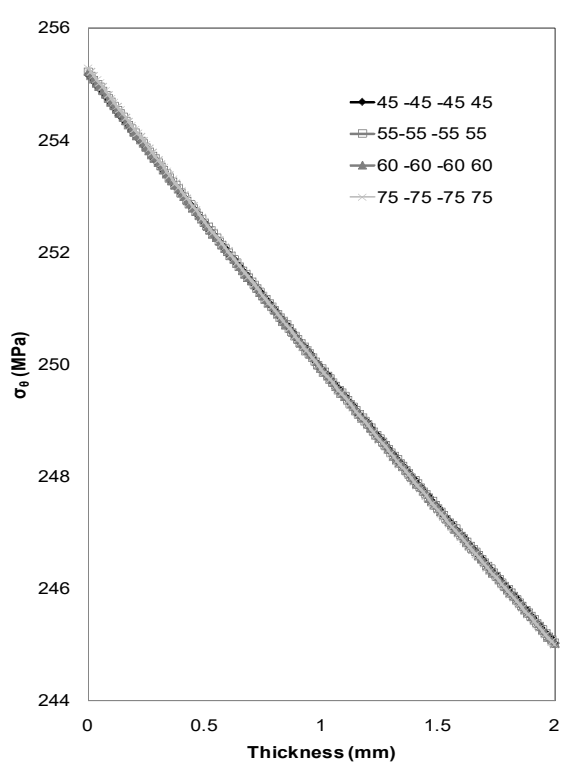

(a)

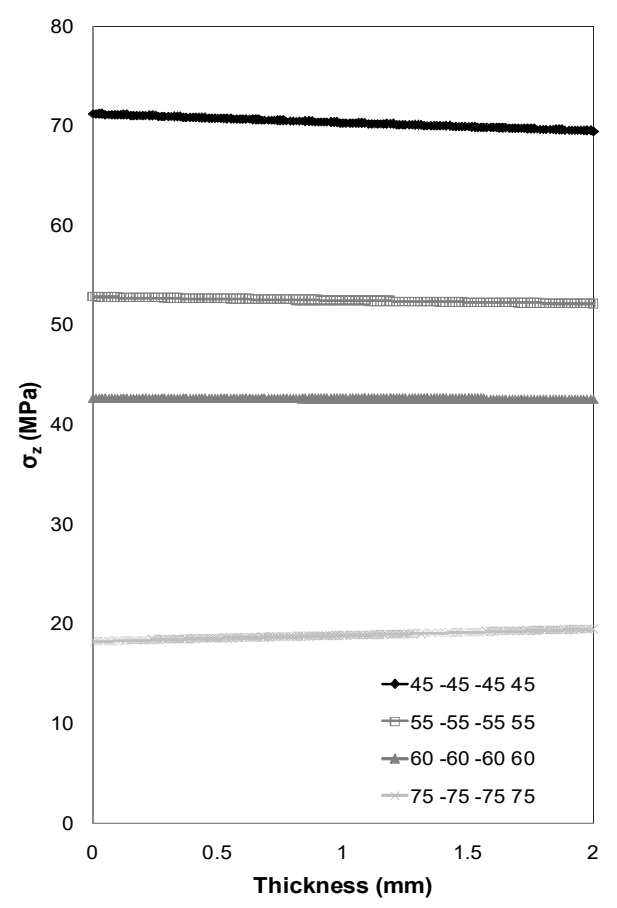

(c)

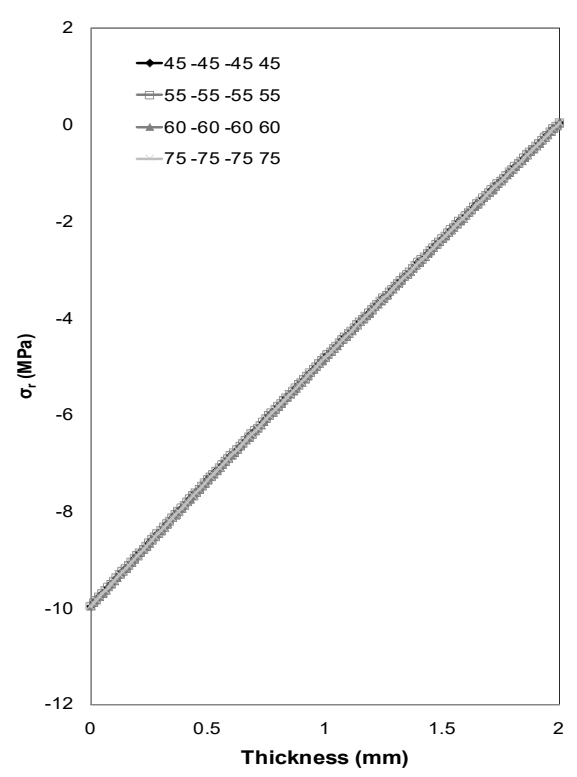

(b)

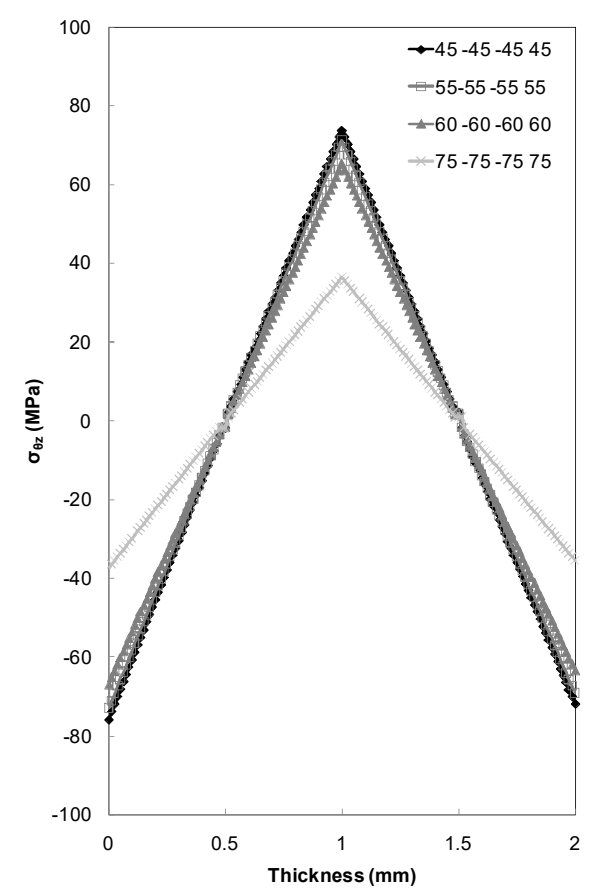

(d)

Fig. 7. The distribution compared of (a) tangential stress, (b) radial stress, (c) axial stress, (d) shear stress through thickness direction for inner surfaces E-glass fibre/epoxy and outer surfaces carbon/epoxy (AS4/3501-6)

As seen Fig.7a and Fig. 8a, the stress values are almost close to each other because of the order of layers and symmetrical arrangement. The stresses of hybrid composite pipes, inner surfaces of model are carbon/epoxy (AS4/3501-6) and its outer surfaces are E-glass fibre/epoxy, are the greater than others.

In Fig. $7 \mathrm{~b}$ and Fig. 8b, the stress values are almost close to each other like in Fig.7a and Fig. 8a because of the order of layers and symmetrical arrangement. Because internal pressure is applied at 
thickness direction. Radial and tangential stresses show the same behavior for both material orientations (E-glass fiber, carbon fiber).

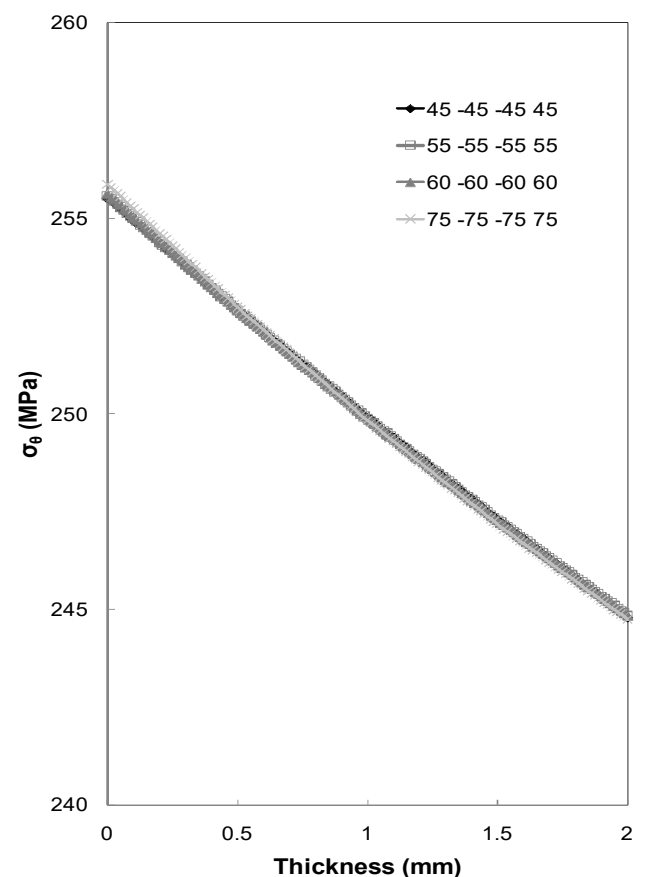

(a)

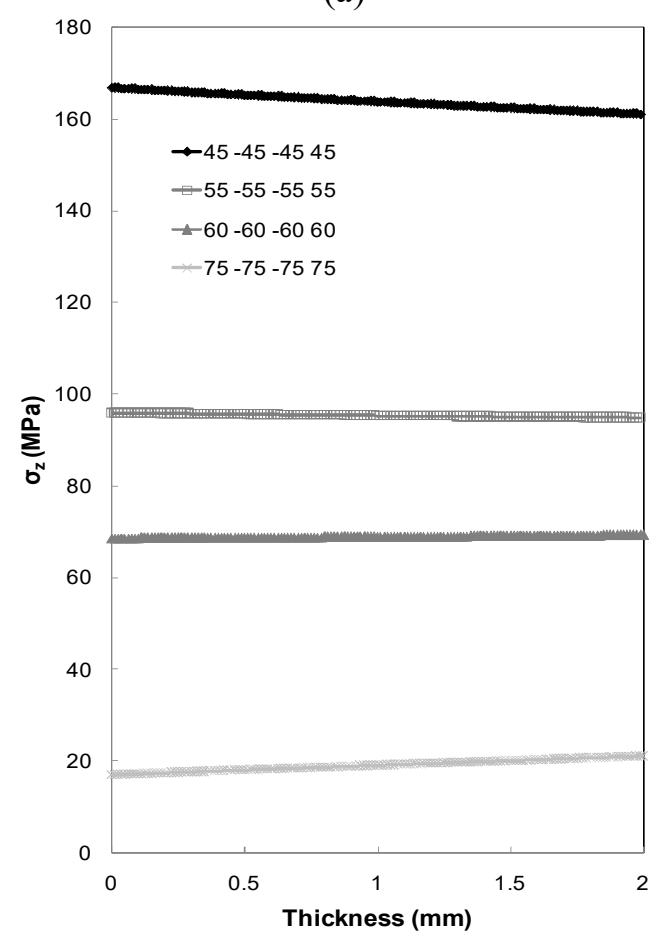

(c)

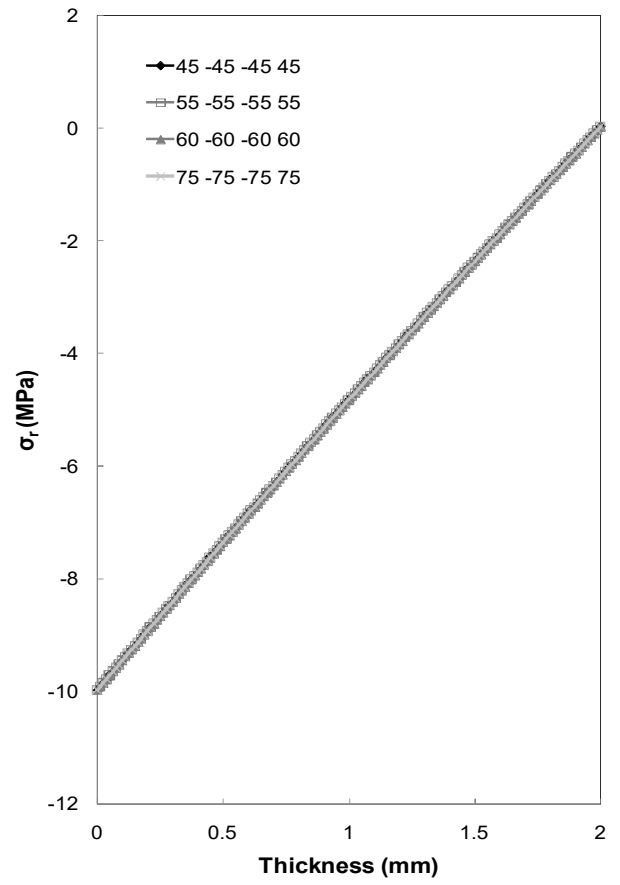

(b)

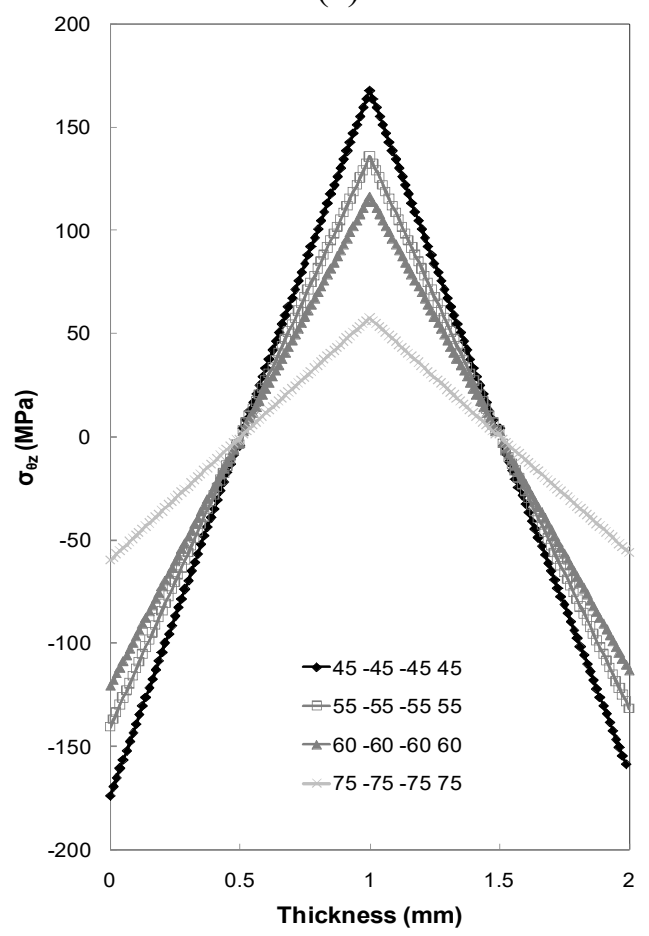

(d)

Fig. 8. The distribution compared of (a) tangential stress, (b) radial stress, (c) axial stress, (d) shear stress through thickness direction for inner surfaces carbon/epoxy (AS4/3501-6) and outer surfaces E-glass fibre/epoxy 
The axial stresses of $\left[45^{0} /-45^{0}\right]_{\mathrm{s}}$ for both material orientations are the greatest from the inner surface to the outer surface of the pipes than other as seen Fig. 7c and Fig. 8c. When inner surfaces of model are carbon/epoxy (AS4/3501-6) and its outer surfaces are E-glass fibre/epoxy is, axial stresses are the greatest.

The shear stresses of $\left[75^{\circ} /-75^{0}\right]_{\mathrm{s}}$ for both material orientations is the smallest from the inner surface to the outer surface of the pipes than other. The shear stresses of $\left[45^{0} /-45^{0}\right]_{\mathrm{s}}$ are greater than others. When shear stress of the model, inner surfaces E-glass fibre/epoxy and outer surfaces carbon/epoxy (AS4/3501-6), is the smallest.

\section{Conclusions}

This study presented the mechanical behavior of a 3D finite element model of multi-layered hybrid composite pipes under internal pressure. The composite pipes were analyzed at different orientation angles and materials orientations. The orientation angles and materials orientations were researched to determine their effects on hoop, axial and shear stresses. Also, behaviors of radial and tangential, axial and shear stresses were examined. Effect of orientation angles were shown as graphical. Furthermore, the effect of material orientations and their rows in layers were investigated. The stresses of $\left[45^{0} /-45^{0}\right]_{\mathrm{s}}$ for both material orientations are the greatest from the inner surface to the outer surface of the pipes than other. Moreover, stress of the model, inner surfaces carbon/epoxy (AS4/3501-6) and outer surfaces E-glass fibre/epoxy, is the greatest.

\section{References}

[1] Xia, M., Takayanagi, H., Kemmochi, K., Analysis of multi-layered filament-wound composite pipes under internal pressure, Composite Structures, 53, 483-491, 2001.

[2] Martens, M., Ellyin, F., Biaxial monotonic behavior of a multidirectional glass fiber epoxy pipe, Composites Part A-Appl. Sci. Technol., 31, 1001-1014, 2000.

[3] Abdul Majid, M. S., Assaleh, T. A., Gibson, A. G., Hale, J. M., Fahrer, A., Rookus, C. A. P., Hekman, M., Ultimate elastic wall stress (UEWS) test of glass fibre reinforced epoxy (GRE) pipe, Composites Part A - Appl. Sci. Technol., 42, 1500-1508, 2011.

[4] Wakayama, S., Kobayashi, S., Imai, T., Matsumoto, T., Evaluation of burst strength of FW-FRP composite pipes after impact using pitch-based low-modulus carbon fiber, Composites Part AAppl. Sci. Technol., 37, 2002-2010, 2006.

[5] Onder, A., Sayman, O., Dogan, T., Tarakcioglu, N., Burst failure load of composite pressure vessels, Composite Structures, 89, 159-166, 2009.

[6] Kaynak, C., Mat, O., Uniaxial fatigue behavior of filament-wound glass-fiber/epoxy composite tubes, Composites Sci. Technol., 61, 1833-1840, 2001.

[7] Rousseau, J., Perreux, D., VerdieÁre, N., The influence of winding patterns on the damage behaviour of filament-wound pipes, Composites Sci. Technol., 59, 1439-1449, 1999.

[8] Mertiny, P., Ellyin, F., Hothan, A., An experimental investigation on the effect of multi-angle filament winding on the strength of tubular composite structures, Composites Sci. Technol., 64, $1-9,2004$.

[9] Sayman, O., Analysis of multi-layered composite cylinders under hygrothermal loading, Composites Part A - Appl. Sci. Technol., 36, 923-933, 2005.

[10] Zhao, J. H., Chen, X., Dharani, L. R., Ji, F. S., Stress analysis of a multilayered composite cylinder with defects, Theoretical and Appl. Fract. Mech., 34, 143-153, 2000. 
[11] Arjomandi, K., Taheri, F., Bending capacity of sandwich pipes, Ocean Engineering, 48, 17-31, 2012.

[12] Tran, P., Ngo, T. D., Ghazlan, A., Numerical modelling of hybrid elastomeric composite panels subjected to blast loadings, Composite Structures, 153, 108-122, 2016.

[13] Ridzuan, M. J. M., Abdul Majid, M. S., Afendi, M., Mazlee, M. N., Gibson, A. G., Thermal behaviour and dynamic mechanical analysis of Pennisetum purpureum/glass-reinforced epoxy hybrid composites, Composite Structures, 152, 850-859, 2016.

[14] Essabir, H., Boujmal, R., Bensalah, M. O., Rodrigue, D., Bouhfid, R., Qaiss, A., Mechanical and thermal properties of hybrid composites: Oil-palm fiber/clay reinforced high density polyethylene, Mechanics of Materials, 98, 36-43, 2016.

[15] Akpinar, S., Aydin, M. D., 3-D non-linear stress analysis on the adhesively bonded composite joint under bending moment, Int. J. of Mechanical Sciences, 81, 149-157, 2014.

[16] Daniel, I. M., Abot, J. L., Fabrication testing and analysis of composite sandwich beams, Composites Sci. Technol., 60, 2455-63, 2000.

[17] Camponeschi, E. T., Compression response of thick-section composite materials, Annapolis, USA: David Taylor Research Center, DTRC-SME-90/60, 1990.

[18] Sülü, İ. Y., Temiz, Ş., Aydin, M. D., Layer effects of multi-layered face to face adhesively bonded composite pipes subjected to internal pressure, Academic Journal of Science, 4(3), 195202, 2015. 